Takanori Tamura, Daiyu Tamura:

\title{
Unsuccessful 'chats' for mutual understanding about religion in the Japa- nese Internet: preliminary studies for global information ethics
}

\begin{abstract}
:
This paper analyzes the structure of unsuccessful chats over the internet about Japanese religions. On the internet, people of different religions and beliefs can easily meet. However, in Japan, chats about religion rarely succeed. This is due not only to a lack of social cues and anonymity but also because there is power balance between two groups, one with a positive attitude towards religion and the other with a negative attitude. Their different pre-understandings of religion make the discussion difficult. It is important to analyze moments of pre-understanding of discussants in order to better understand the dynamics. We present an approach for such analysis based on Paul Ricoeur's theory for "Threefold Mimesis." This is a trial for successful communication among people from different cultures and societies via the internet. It could be a step forward in achieving the global information ethics that Charles Ess claims. This is because differences in the pre-understanding of a topic are an essential problem there.
\end{abstract}

\section{Agenda:}

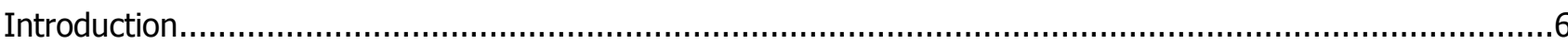

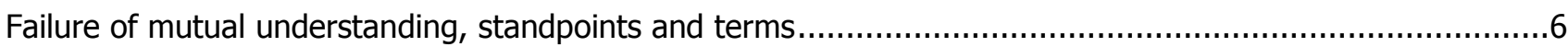

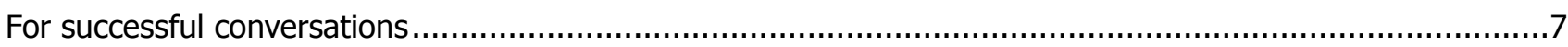

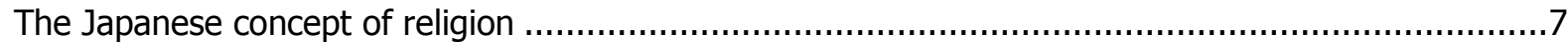

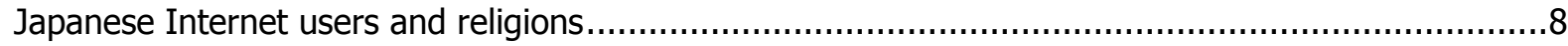

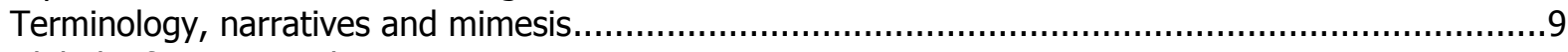

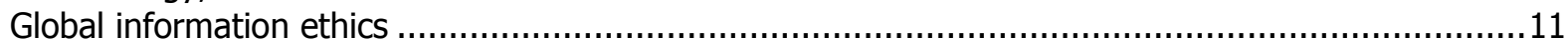

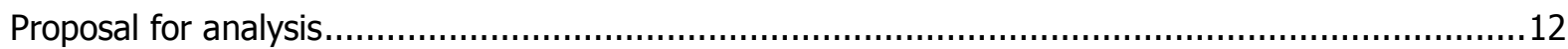

\section{Authors:}

Dr. Takanori Tamura:

- General Education Division, Seigakuin University, 1-1, Tozaki, Ageo City Saitama Pref., Japan.

- $\square$ tamuratak@mtb.biglobe.ne.jp, 且 http://tamura.jpn.org/

- Relevant publications:

- Tamura, Takanori: How Does the Internet Work for Religions Based in Japan?, Tsukuba annals of sociology, 10, 1998. 21-38.

- Kawabata, Akiara and Tamura, Takanori : Online-religion in Japan: Websites and religious counseling from a comparative cross-cultural perspective. Journal of Computer-Mediated Communication, 12(3),2007. May 26, 2008.

Daiyu Tamura:

- Independent Researcher, Kichijoji, Musahino City, Tokyo, Japan.

- $\square$ daiyutamura@tamura.jpn.org 


\section{Introduction}

The aim of this paper is to analyze the structure of unsuccessful chats for mutual understanding about Japanese religions in the internet. According to Paul Ricoeur's theory, we will argue that this difficulty occurs because people have different pre-understandings of the topic. This issue is also preliminary preparation for Charles Ess's global information ethics. He foresees a global information ethics that achieve normative legitimacy among a wide diversity of cultures and ethical traditions in local and global situation ${ }^{1}$.

Between about 1995 and 2000, at the first stage of the internet era in Japan, religious institutions and researchers had some expectations of the internet for religious activities like propagation, rituals and prayer $^{2}$. Such discussions have stagnated recently, and religious organizations do not have such high expectations for the Internet at this time ${ }^{3}$.

However, discussions about religion exist widely and continue in the Japanese internet. For example, more than 700 threads were built in Ni chan'neru (Channel 2), the biggest, extremely anonymous and sometimes infamous BBS. There are many online communities for religion in Mixi, the biggest Social Network Service in Japan.

Given both the quantity and continuity of this phenomenon, the expansion of chats about religion cannot be disregarded. The issue has hardly been taken up by the researchers, however, because chats about religion by common people have not been recorded and, as such, have not been researchable before the internet. Since dialogues in the internet are written text, they are visible and researchable insofar as research ethics allows.

${ }^{1}$ Ess, Charles, Ethical Pluralism and Global Information Ethics (a). 1.

2 International Institute for the Study of Religion (ed.) : Internet Jidai no Syukyo.

3 Kawabata and Watanabe: Communication Gap between Believers and Non-believers in Religion. 5,7 .
Unfortunately, chats about religion rarely succeed in achieving mutual understandings. ${ }^{4}$ The internet provides people with opportunities to communicate with other people, who are of a different religion, have different customs or different conceptions and understandings of particular matters. While this may be good, it may also invite misunderstandings and arguments. We presume that their failure to achieve mutual understanding is because of their differences in pre-understanding concerning religion. We think that analysis of internet chats about religion would help us to figure out the difference. Although, we deal with domestic matters, this failure is part of the cultural differences Ess deals with in his global information ethics.

We argue this issue based on empirical research and religious studies influenced by narratology. In order to understand their difference with reference to standpoints and the issue of terms, we would like to provide

a) some examples of chats;

b) an outline of Japanese religions;

c) religious interests of the Internet users; and

d) a theoretical explanation for terms and preunderstandings by Ricoeur's theory and global information ethics.

\section{Failure of mutual understanding, standpoints and terms}

I chose some examples of failure of mutual understanding among believers and non-believers from the Ni chan'neru (Channel 2) BBS 5 .

On a Christianity thread, non-believer poster $A$ simply asked a question about "original sin" and other basic concepts. He asked, "If you presume original sin, is there any practical benefit for your life or thought?"

A non-believer, poster $B$, replied,

It is not beneficial but does huge harm to the human psyche. "Groundless guilt" is a typical symptom of depression, and it is nothing but the

\footnotetext{
${ }^{4}$ Watanabe, Mitsuharu: Conflict and Intolerance in a Web Community: Effects of a System Integrating Dialogues and Monologues.
}

${ }^{5}$ Ni chan'neru can be freely quoted. 
object of treatment. Christianity plants the concept of guilt and makes people believers. That is a threat. Threat is the essence of Christianity.

A Christian poster $C$ replied, "Then, why is there suffering, unfairness, and death?" because he thought 'original $\sin ^{\prime}$ was the reason for such concerns. However, a non-believer, poster $D$, replied, "That is evidence of God's absence." They are talking about the same reality, namely, suffering, unfair and death, from opposite presuppositions. Also, the term 'original $\sin ^{\prime}$ is difficult to understand for Japanese especially because there is only one word, tsumi for 'sin' and 'guilt' in Japanese.

In a thread "How do we increase the number of Christians in Japan?" built by a non-believer, there are plural critical opinions about Christians in Japan. For example, "The Christians I know always have the attitude of teaching something to others," "People involved in religions are difficult to associate with indeed." "Christians get angry when they are asked questions they cannot answer and consider the questioner to be Satan." Some manners rather than teaching are the problem here. A non-believer, poster $E$, posted about Christians' comments,

Christians' comments are often comprehensible to only Christians. Why can't they use common phrases to reach non-Christians?

With regard to this thread, there is one Christian who repeatedly posts only words from the Bible with no explanation and ultimately strengthens others' antipathy. The examples indicate that terms and discourse manner are crucial for disagreement. The importance of terms and discourse manner is the same for Buddhism cases.

On a thread concerning Buddhism, there was talk about the concept of Rinnne Tensho (reincarnation in Buddhism). After a poster explained it, poster $F$ wrote,

Still I can't understand what Rinnne Tensho is. If it exists, in what way does it exist? If it does not exist, in what way doesn't it exist? For example, mirages exist because they are visible, but they don't not exist because they are not physical entities. What is the case for Rinnne Tensho?

He got answers like, "The question was wrong. The right question is not the one that asks for an answer but the one that asks for the way to get an answer," and "You don't practice training and repeating primitive questions." Poster $F$ wrote again,

One says you need Satori to understand it and the other says it is a primitive question. Why can't you teach me if the question is primitive?

In examples, we find that a) their standpoints (perspectives) are quite different and $b$ ) the difference appears to be an issue of terms and manner of discourse as poster $E$ claimed obviously. These two things are related and discussed in this paper.

\section{For successful conversations}

\section{The Japanese concept of religion}

We would like to explain the Japanese concept of religion through results of empirical surveys. Table 1 shows results of the questions "Do you have belief?" ('belief') and "Do you have religious attitude?" ('religious attitude'). Only about $30 \%$ of population claimed to have 'belief. However, about $70 \%$ of population have 'religious attitude'. Even amongst the people with 'no belief, $60-70 \%$ of them claim to have 'religious attitude'. They are religious even when they claim not to have belief in religion. It reflects the reality in Japan in that few people say that they have the religion, but most participate in Buddhism rituals every August and go to Shrines in January each year ${ }^{6}$.

This is different from other parts of the world where Christianity or Islam is dominant. Sometimes this difference has been used as an example of how Japan is odd, complicated and different from other countries. However, it is supposed to boast of Japan in the paradox. It is criticized as transformed ethnocentrism ${ }^{7}$. Fumi Hayashi conducted a meta-analysis of plural survey records and pointed to just the opposite phenomenon whereby, in western countries (Germany, the Netherlands and England), more than $10 \%$ of the population answered that they had both "belief" and "no religious attitude ${ }^{8}$." Contrary to the Japanese case, respondents claimed to be not

${ }^{6}$ Amari, Toshimaro: Nihonjin ha Naze Musyukyo Nanoka. 14-15.

7 Iwai, Hiroshi: Nihon Syukyo no Rikai ni Kansuru Oboegaki. 81.

${ }^{8}$ Hayashi, Fumi: Syukyo to Soboku na Syukyoteki Kanjo. 16. 
Table 1: "Belief" and "importance of religious attitude" in Japan, change in time series (\%)

\begin{tabular}{lcccccc}
\hline research year & 1983 & 1988 & 1993 & 1998 & 2003 \\
\hline "belief" & 32 & 31 & 33 & 29 & 30 \\
"importance of religious attitude" in "belief" & 94 & 93 & 94 & 93 & 94 \\
"importance of religious attitude" in "no belief" & 73 & 63 & 61 & 58 & 60 \\
"importance of religious attitude" in whole & 80 & 72 & 72 & 68 & 70 \\
\hline
\end{tabular}

This table is cited and modified from a table in Hayashi (2006.) "Belief" is ratio for "yes" and "no belief" is answer for "no" to a question, "Do you have belief?" "Importance of religious attitude" is ratio for yes to a question, "Do you have religious attitude?"

religious even they had religious beliefs. Each culture has its own complexity and variety.

Additionally, since the Japanese word Syukyo (religion) is a translation from German, it reminds Japanese people that Christianity or other monotheisms (although there are no 100\% monotheistic religions.) ${ }^{9}$ For this reason, the Japanese do not include indigenous religions, like Shintoism, Buddhism and other folk religions, into categories of Syukyo. Religious scholars divide Japanese religions into two groups: "religion of awakened belief" vs. "unaware religiosity ${ }^{10 "}$ or "founded religion" vs. "natural religion. ${ }^{11 "}$ The Japanese word Syukyo refers to the first understanding of religion in both cases. In addition to this, many Japanese have a negative image of religion, particularly of new religions ${ }^{12}$. This attitude was strengthened by the subway sarin gas attack perpetrated by Aum Shinrikyō in 1995.

Thus, there are some kinds of people who have different standpoints concerning religion. Such standpoints are reflected in the difference of posters in the examples. In the examples and this paper, we

${ }^{9}$ Iwai, Hiroshi: Nihon Syukyo no Rikai ni Kansuru Oboegaki. 80.

10 Inoue Junko: Syukyo Syakaigaku no Susume (Guide book for Religious Sociology) . 26, 31.

${ }^{11}$ Amari, Toshimaro: Nihonjin ha Naze Musyukyo Nanoka. 11.

12 Tamura, Takanori: Denshi Network Riyo to Syukyokan, Kachikan, Taikendan Kokan ni Knasuru Chousa Kaidai. 138. deal with issues between believers and nonbelievers. Since there are few believers, this issue is more significant than the issue of one religion or another, such as Christianity and Islam.

\section{Japanese Internet users and religions}

In order to deepen our understanding of the findings in the former section and understand the Internet users' perspectives concerning religion, we draw on the results of a survey ${ }^{13}$. It helps to describe the attributes of discussants.

To the request, "Please tell me your religious interest", choices from a given list were as follows: (1) I have faith, $25 \%$, ('faith'), (2) I do not have faith but I AM interested in religion, $25.5 \%$, ('no faith interest'), (3) I do not have faith and I HATE religion, $49.5 \%$, ('haters') ${ }^{14}$. We combined the categories 'faith' and 'no faith interest' to create a positivelyinterested-in-religion group ('positive'), and classified the rest as negatively-interested-in-religion ('negative') (Table 2). The 'positive' group comprised $50.5 \%$ of the respondents; the 'negative' group $49.5 \%$.

\footnotetext{
${ }^{13}$ Regis survey, 2003.
}

${ }^{14}$ We exclude "I do not have faith and I am NOT interested in religion" group from the original result because they are not related to religious discussion. 
Table 2 Interest in Religion among Internet users in Japan

freq. $\% \quad$ classification

Currently, I have (religious) faith

$10125.0 \quad$ positive

Although I do not have any particular faith, I am interested in religion. $\quad 103 \quad 25.5$

I do not have any particular faith and I would rather hate religions. $\quad \begin{array}{llll}200 & 49.5 & \text { negative }\end{array}$

$\begin{array}{lll}\text { Total } & 404 & 100.0\end{array}$

This table is based on Regis research in 2003. Total answers were 876. We excluded 472 "yes" answers for "I do not have any particular faith and I am not interested in religion."

Firstly, if we can generalize from the survey results and infer that the distribution among discussants is the same, this equilibrium may be one of the reasons for difficulties and continuance of discussion about religion in the Internet. Discussion is difficult because the 'positive' and 'negative' are equallyrepresented powers. This is because opposite opinions are hardly compromised. Also, while the majority usually absorbs the minority, this does not happen here because they are evenly matched. For the same reasons, discussions persist - each side is positively or negatively interested in religion and keep a seesaw game moving.

Secondly, from the point of view of the 'faith' group, two-thirds of their debaters are religion haters ('haters'). This is not a favorable situation for them. Additionally, the 'no faith interest' group is not necessarily comprised of potential believers. Although we need further research, we can infer that they are "no faith" not because of their ignorance; they can easily get information from the Internet but remain 'no faith' even after learning much about religions ${ }^{15}$. The same is true of persons in the 'faith' and 'haters' categories ${ }^{16}$. After receiving much information from

${ }^{15}$ See not direct but related discussion based on socio psychological computer simulation. Shimura et al.: Kakudaisuru Network ha Syosuha wo Zanson Saseruka: DSIT Simulation ni Okeru Hikinsetsu Tasya Joho no Donyu.

${ }^{16}$ Before the Internet, giving information to followers worked for anti-cult movement because the the Internet, they might become more hardened and fixed to their positions-unwilling to compromise. We found a reason for unsuccessful and continuous discussion about religion besides the general reasons including, for example, a lack of social cues, etc ${ }^{17}$.

This analysis shows why their perspectives are different in the examples. They cannot communicate well because their standpoints concerning religion are different. Some posters think that religion is evil and others think that religion is highly significant and that others are interested in religion but cannot understand the words of believers, as claimed by poster $E$. Their differences appear in their manners of discourse and terminology. We can give a theoretical reason for relationship of their standpoints and terminology.

\section{Terminology, narratives and mimesis}

In the examples, we have shown how terminology differences between believers and non-believers affect mutual understanding among them as we quote poster $E$. Kawabata and Watanabe conducted a survey concerning impressions of sentences by

followers had little information outside the organizations. See Kito, Masaki: Centripetal Force and Centrifugal Force of Religious Web Site from Point of View of Trial that Relates to Religion.

${ }^{17}$ Kiesler and McGuire: Social Psychological Aspects of Computer-Mediated Communication. 
non-believers. They asked participants to read two documents containing similar claims and information, one written in traditional "religious" language and the other in contemporary non-religious language. They found that most subjects showed a strong discomfort with the former religious document and they were generally receptive to the latter non-religious document ${ }^{18}$. Miscommunication among groups occurs - at least partially - because of differences in terms and narratives.

Why do religious differences appear in the manner of discourse and the terminology? That is also a problem of what constitutes being a believer. According to religious studies under influence of narratology, an aspect of belief is a process of achieving technical terms and narratives of the certain religion. The more one understands the terms of a religion, the more one becomes a mature believer. He re-interprets and explains his life with the terms and narratives of the religion. Over time, the terms and narratives of the religion come to be embedded in the life stories that are expressions of his identity ${ }^{19}$. Those terms and narratives have become their pre-understandings concerning religions.

In order to understand the structure of pre-understanding, narratives and how human interpretation works, we refer Paul Ricoeur's theory for "Threefold Mimesis." Mimesis, a word in Aristotle's Poetics, means "imitation". It can also be understood to mean a reflection of the world that is a reconstruction and presentation of reality. Although a narrative is a series of events, each event and experience is not yet part of a narrative. They have to be located in some understandable order by authors as a narrative. That is the function of mimesis. In this sense, mimesis is similar to emplotment. Paul Ricoeur went far beyond this in his deliberation about power of mimesis. He wrote that there are three moments in mimesis. They are related and circu-

\footnotetext{
${ }^{18}$ Kawabata, Akira and Watanabe, Mitsuharu: Communication Gap between Believers and Nonbelievers in Religion. 9-14.

${ }^{19}$ Iwai, Hirsoshi: Syukyo no Chisiki Keieiron (On the Knowledge Management of Religions). 78, Kawabata and Watanabe: Communication Gap between Believers and Non-believers in Religion. 9.
}

lated. He named each element as Mimesis 1, 2 and 3 , respectively ${ }^{20}$.

Mimesis 1 is the pre-understanding of human action. To imitate or represent action is first to pre-understand what human action is, in its semantics, its symbolic system, its temporality. Upon this preunderstanding, common to both poets and their readers, emplotment is constructed and, with it, textual and literary mimetics. Ricoeur calls it prefiguration of the practical field. Mimesis 2 is Aristotle's mimesis. It is a function of configuration and it constructs and represents the reality. Mimesis 2 constructs plots. Emplotment is the operation that draws a configuration out of a simple succession. Mimesis 3 succeeds procedure and it marks the intersection of the world of the text and the world of the hearer or the reader. That is refiguration of the practical field through the reception of the work. This interpretation produces the next pre-understandings. In that way, Ricoeur showed prior and succeeding procedure of this mimesis $2^{21}$.

This is a theoretical background for how terms and narratives of their religion became their preunderstandings concerning religion. As a process of mimesis 1 , they have their pre-understandings (terms of their religion), and as mimesis 2, they construct their religious self stories. Their stories are listened to and shared with their communities in mimesis 3 and become their own and others' preunderstandings again (the circulation of mimesis.) This is also applicable to non-believers because mimesis theory is a general theory for human interpretation.

In the former section, we introduced three groups, 'faith', 'no faith interest,' and 'haters'. These three categories of people each have their own terms and narratives that consist of their pre-understandings of religion. That is why poster $E$ expressed his annoyance about Christians' terminology and is a reason for mutual misunderstandings.

This circulation is very apt for the analysis of chats about religions on the Internet. This is because chats - conducted through the exchange of texts on the Internet - is a co-authoring process of a new narrative. Each author has a different understanding of religion and the terminology as pre-understanding

20 See Flick, Uwe: An introduction to qualitative research. 86-88.

${ }^{21}$ Ricoeur, Paul: Time and Narrative 1. 64-71. 
(mimesis 1). They then write a new text through interaction (mimesis 2). Readers read the text and interpret it (mimesis 3). They can refer and understand what past writers shared ${ }^{22}$. Thus, written coauthored text will be read, interpreted and become the next pre-understanding (circulation of mimesis). Internet text is down-to-earth practice of Ricoeur's theory. The Internet made this process faster and visible. Analysing Internet chat for religions will help us to concretely recognize what kind of pre-understanding they possess. This does not immediately lead to an agreement among discussants but helps them to understand why they cannot agree with one another.

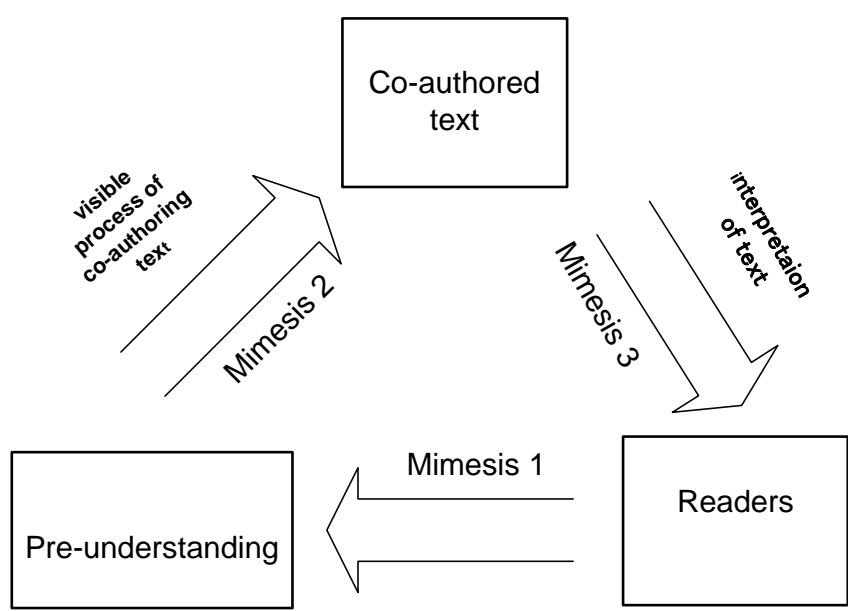

Figure 1 Circulation of Mimesis as co-authoring and interpretation in the Internet. This figure is based on Flick $2006^{23}$.

\section{Global information ethics}

Communication difficulties due to religious difference are one with which Charles Ess concerns himself in his global information ethics. According to Ess, global information ethics must

(a) address both local and global issues evoked by ICTs / CMC, etc. ,

(b) in ways that both sustain local traditions / values / preferences, etc. and

(c) provide (quasi-) universal responses to central ethical problems ${ }^{24}$.

${ }^{22}$ Kato and Akahori : Influences of Past Postings on a Bulletin Board System to New Participants in a Counseling Environment. 1549-1557.

${ }^{23}$ Flick, Uwe: An introduction to qualitative research. 88.
That is, Ess foresees a global information ethics that achieve normative legitimacy among a wide diversity of cultures and ethical traditions based on ethical pluralism. Ethical pluralism seeks to avoid imperialistic homogenization and conjoins shared norms while simultaneously preserving the irreducible differences between cultures and peoples. It differs from ethical relativism which denies ethical dogmatism and abandon to seek global norms. While ethical relativism may have played an important role in shaping the Western liberal nation-state, it makes it impossible for us to condemn the views, values and acts at work in genocide, slavery, and dictatorship. Moreover, Ess claimed, that relativism was taken as a warrant for fascism ${ }^{25}$.

Analysis of Internet chats about religion will offer findings which contribute to Ess' discussion in the following ways.

(1) While we have discussed a domestic issue, it is related to the global information ethics that covers international and intercultural issues. This is because global information ethics should be applied to not only international issues but also domestic issues. Then, we dealt with the failures of religious discussion that were typical cases of cultural difference, which were based in differences of assumption, context, and pre-understanding.

(2) Analysing pre-understanding is related to ethical pluralism. Ethical pluralism does not intend to reconcile differences, but it seeks applicable ethics beyond the difference. For that purpose, we need to know precisely how they are different. If we find a way to analyze the precise structure of pre-understandings, we can contribute to ethical pluralism.

(3) The text in the Internet is unedited co-authored text by common people. This is important because global information ethics must be practical and applicable to daily situation of common people.

As we described previously, the Japanese situation mentioned above is not one conducive to having successful Internet chats about religion. Yet, it is a situation that presents the possibility of inventing new values which are not found in homogeneous environments. In ethical pluralism, it is crucial that

\footnotetext{
${ }^{24}$ Ess, Charles, Ethical Pluralism and Global Information Ethics (a). 1.

25 Ess, Charles: Ethical Pluralism and Global Information Ethics (b). 215-216.
} 
people can bond not in spite of but precisely because of difference. As Ess quotes Taylor, "They can sense, that is, that their lives are narrower and less full alone than in association with each other. ${ }^{26 \prime \prime}$

\section{Proposal for analysis}

According to the theory mentioned above, productive conversation is building common terms and narrative in the mimesis circulation. In order to make it possible, we need hermeneutical deliberation about the way in which people's beliefs, thoughts and narratives were constructed in the circulation. Being aware of this structure helps one to find points of agreement among groups which have different pre-understandings. That is related to the way of Ess's ethical pluralism.

Hints for process of the strategy will be found in the analysis of practical knowledge of people's conversation. We should find and analyze successful cases to get a hint. Possible objects would be online counselling and self-help groups. In Japan, we found some counselling services by religious organizations $^{27}$. At the beginning, they have no shared preunderstanding, then, a member or a client tells of his or her personal experiences. Counsellors and group members try to listen with empathy to those experiences and to understand them. This is an interactive process of sharing pre-understandings.

Literature on narrative analysis related to mimesis theory, regarding religion, includes Kikuchi $(1998)^{28}$ and Akiba and Kawabata (2004) ${ }^{29}$, Kawabata and Watanabe $(2006)^{30}$ and literature pertaining to self help groups include Ito $(2005)^{31}$ but they are not

${ }^{26}$ Ess, Charles: Ethical pluralism and global information ethics (b), 217.

${ }^{27}$ Kawabata and Tamura, : Online-religion in Japan: Websites and religious counseling from a comparative cross-cultural perspective.

28 Kikuchi, Hiroo: Shin'nyoen "Seinenbu Benron Taikai" ni Miru Jiko no Kosei to Hen'yo: Shin'nyoen. Shinsyukyo Kenkyu heno JikoMomonogariron teki Approach no Kokoromi.

${ }^{29}$ Akiba and Kawabata: Reino no Reality he: Syakaigaku Shin'nyoen he Hairu.

30 Kawabata and Watanabe: Communication Gap between Believers and Non-believers in Religion.

${ }^{31}$ Ito, Tomoki: Tamerai no Koe: Self Help Group Genyukai heno Narrative Approach. about Internet text. Tamura (2006) ${ }^{32}$ examines Internet text but does not deal with religion. We can apply these various treatises to the study of religion text in the Internet from the point of view of communication and ethical pluralism.

Acknowledgment. We thank Professor Nakada Makoto for his letting us use the survey data, and our reviewers for their educational comments. We also want to thank Carol Christine McKetty (Ph.D candidate) and Dr. Leslie M. Tkach-Kawasaki for their comments and checking our English.

\section{References}

Akiba, Hirhoshi and Kawabata Akira: Reino no Reality he: Syakaigaku Shin'nyoen he Hairu (A. Reality of Medium; Sociology of Shin'nyoen), Tokyo: Shinyosya 2004.

Amari, Toshimaro: Nihonjin ha Naze Musyukyo Nanoka, Tokyo, Chukuma Shobo, 1996. (Warum sind Japaner areligiös?, München: Iudicium 2004 [German Translation]).

Ess, Charles, Ethical Pluralism and Global Information Ethics (a), In Proceeding of Uehiro-Carnegie Conference on Information Ethics, University of Oxford, St. Cross College 2005.

Ess, Charles: Ethical pluralism and global information ethics (b), Ethics and Information Technology, 8 (4) 2006, 215-226.

Flick, Uwe: An introduction to qualitative research 3rd, SAGE 2006.

Hayashi, Fumi: Syukyo to Soboku na Syukyoteki Kanjo (A Study of Religious Faith and Religious Feelings), The Japanese Journal of Behaviormetrics, 33 (1) 2006,13-24

Inoue Junko: Syukyo Syakaigaku no Susume (Guide book for Religious Sociology). Maruzen 2002.

Internationonal Institute for the Study of Religion (ed): Internet Jidai no Syukyo (Religion in the Interent Age), Tokyo: Shinsuokan 2000.

Ito, Tomoki: Tamerai no Koe: Self Help Group Genyukai heno Narrative Approach (Voice of Hesitation: Narrative Approach to a Self Help Group Genyukai), Soshioroji, 50. 2005(2) 3-18.

Iwai, Hiroshi: Nihon Syukyo no Rikai ni Kansuru Oboegaki (Notes on the Understanding of Japa-

32 Tamura,Takanori: Niho no Internet ni Okeru Jikomonogatriteki Communication to Imikukan. 
nese Religion), The bulletin of Kansai University of International Studies, 5, 2004, 79-89.

Iwai, Hiroshi: Syukyo no Chisiki Keieiron (On the Knowledge Management of Religions), The bulletin of Kansai University of International Studies, 16, 2005, 75-85.

Kato, Shogo and Akahori, Kanji : Influences of Past Postings on a Bulletin Board System to New Participants in a Counseling Environment, Proceedings of ICCE 2004, 1549-1557 Online: http://www.ak.cradle.titech.ac.jp/papers/pdf/IC CEShogoKATO.pdf May 26, 2008.

Kawabata, Akiara.and Tamura, Takanori : Onlinereligion in Japan: Websites and religious counseling from a comparative cross-cultural perspective. Journal of Computer-Mediated Communication, 12(3), 2007. May 26, 2008.

Online:

http://jcmc.indiana.edu/vol12/issue3/kawabata. html May 31, 2008

Kawabata, Akira and Watanabe, Mitsuharu: Communication Gap between Believers and Nonbelievers in Religion, Association of Internet Researchers Conference, Brisbane, Australia, September 29, 2006, presentation.

Kiesler, S., Siegel, J. \& McGuire, T.W.: Social Psychological Aspects of Computer-Mediated Communication, American Psychologist, 1984. 39, 1123-1134.

Kikuchi, Hiroo: Shin'nyoen "Seinenbu Benron Taikai" ni Miru Jiko no Kosei to Hen'yo: Shin'nyoen Shinsyukyo Kenkyu heno JikoMomonogariron teki Approach no Kokoromi (Construction and modification of Self in Shin'nyoen "Seinenbu Benron Taikai": Self-narrative approach to Shin'nyoen Studies), Religion \& society, 4, 1998. 107-208.

Kito, Masaki: Centripetal Force and Centrifugal Force of Religious Web Site from Point of View of Trial that Relates to Religion, presentation for Centripetal Force and Centrifugal Force to the Religious Community Brought by the Internet, the Internet and Religion Project, The Japanese Association for the Study of Religion and Society, March, 2001.

Online:

http://wwwsoc.nii.ac.jp/jasrs/about/jasrscmc/meeting2001/kito.html May 26, 2008

Ricoeur, Paul.: Time and Narrative 1, translated by Kathleen McLaughlin and David Pellauer. University of Chicago Press, 1984.

Regis survey, 2003, unpublished, Internet Communication to Kachi ya Kanjo tono Kankei ni tuite no Chousa (Internet Communication, Value and Emotion), Conducted by Nakada Makoto (Tsukuba University) and group Regis.

Shimura, Makoto et al.: Kakudaisuru Network ha Syosuha wo Zanson Saseruka: DSIT Simulation ni Okeru Hikinsetsu Tasya Joho no Donyu (Does Extending Social Networks Help a Minority to Survive?: On the Introduction of Information about Distant Others to a DSIT simulation).

Tamura, Takanori: Denshi Network Riyo to Syukyokan, Kachikan, Taikendan Kokan ni Knasuru Chousa Kaidai (Explanatory Notes For a Reserach on Degital Network Use and Religion, Value and Narrative Exchange) in Ishii, Kenji, Basic Research For Information Society and Religion, Report for Grant-in-Aid for Scientific Research, 2003, 87-154 (The research was conducted by Nakada Makoto and research group Regis).

Tamura, Takanori: Niho no Internet ni Okeru Jikomonogatriteki Communication to Imikukan (Selfnarrative Communication and Meaning Space in Japanese Internet) Unpublished doctoral dissertation, University of Tsukuba, 2006.

Watanabe, Mitsuharu: Conflict and Intolerance in a Web Community: Effects of a System Integrating Dialogues and Monologues, Journal of Computer-Mediated Communication 12 (3) , 2007. 1020-1042 Online: http://www.blackwellsynergy.com/doi/pdf/10.1111/j.10836101.2007.00361.x May 26, 2008. 